\title{
Mechano-Chemically Activated Fly-Ash and Sisal Fiber Reinforced PP Hybrid Composite With Enhanced Mechanical Properties
}

\section{Atul Kumar Maurya}

IIT Roorkee: Indian Institute of Technology Roorkee

\section{Rupam Gogoi}

IIT Roorkee: Indian Institute of Technology Roorkee

Gaurav Manik ( $\sim$ gaurav.manik@pe.iitr.ac.in )

IIT Roorkee: Indian Institute of Technology Roorkee https://orcid.org/0000-0002-3306-3986

\section{Research Article}

Keywords: Hybrid composites, Natural Fiber, Fly-ash, C-tab, Micromechanical modelling, Sustainable development.

Posted Date: February 15th, 2021

DOl: https://doi.org/10.21203/rs.3.rs-184372/v1

License: (c) (i) This work is licensed under a Creative Commons Attribution 4.0 International License. Read Full License 


\section{Abstract}

This study explores the hybridizing effect of mechano-chemical activated fly-ash (FA) in sisal fiber reinforced polymer composites. Activation and resistance against agglomeration of FA has been achieved by modifying it with 2,4 , and 6 wt. \% of the cetyltrimethylammonium bromide (C-tab). FA activation with $\mathrm{C}$-tab and particle size reduction to nano-level $(<1 \mu \mathrm{m})$ have been appropriately achieved with a planetary ball milling and the same has been confirmed from the dynamic light scattering technique. The hybrid composite containing $25 \mathrm{wt} . \%$ of sisal fiber and $5 \mathrm{wt} . \%$ of ( $6 \mathrm{wt} . \% \mathrm{C}$-tab) treated FA shows much improved tensile (40.12 MPa), flexural (53.27 MPa), and impact strengths $\left(0.75 \mathrm{~kJ} / \mathrm{m}^{2}\right)$ than that of neat PP and composite reinforced with only $30 \mathrm{wt} . \%$ of sisal fiber. This increase in tensile and flexural strength was $30.54 \%$ and $48 \%$ higher than neat PP. Maximum notched impact strength of 0.80 $\mathrm{kJ} / \mathrm{m}^{2}$ have been reported by hybrid composite containing FA treated with $2 \mathrm{wt} . \%$ of the C-tab. Micromechanical modelling using a combination of rule of mixture and inverse rule of mixture separately with Halpin-Tsai predicted a value close to the experimental Young's modulus. DSC studies showed an increment in the composite's crystallinity upon fiber addition. Morphological analysis of the hybrid composite revealed good wettability of reinforcing fiber and FA within the matrix, whereas TGA showed an improved thermal stability of the composites.

\section{Full Text}

This preprint is available for download as a PDF.

\section{Figures}




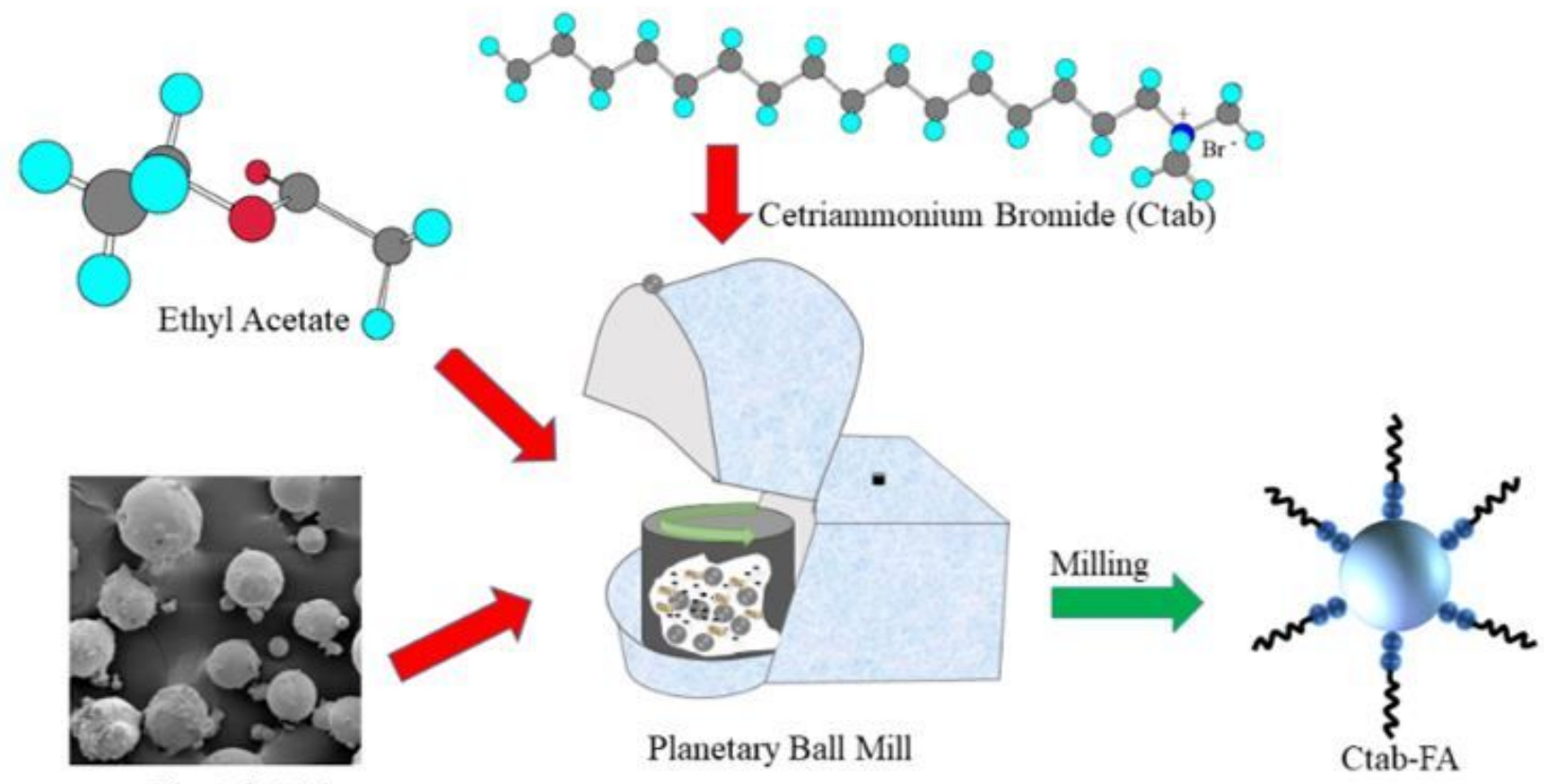

Fly Ash (FA)

Figure 1

Illustration of high energy ball milling of FA in a planetary ball mill. 


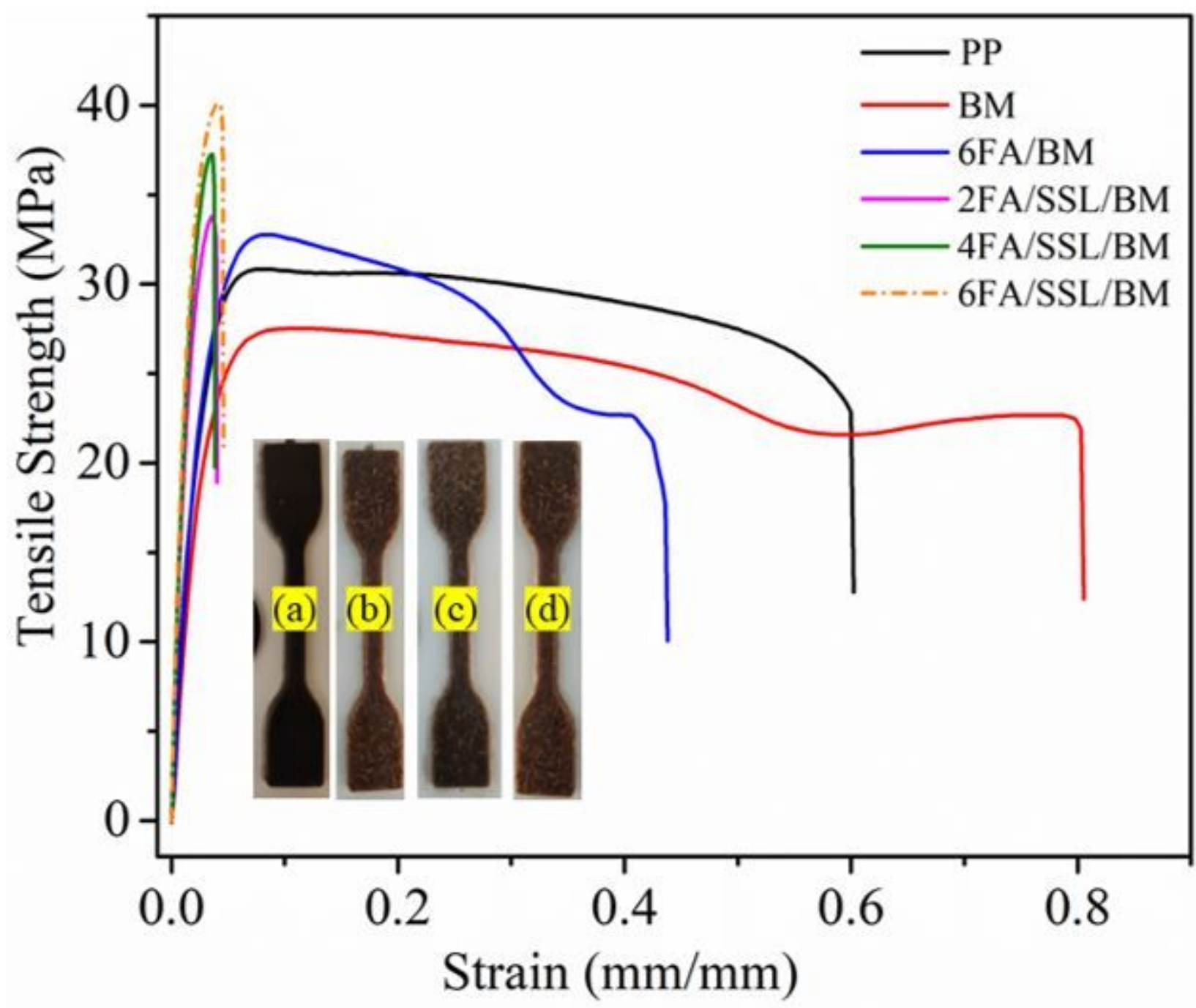

Figure 2

Tensile stress vs. strain curve for hybrid composites and tensile specimen of (a) 6FA/BM (b) 2FA/SSL/BM (c) 4FA/SSL/BM (d) 6FA/SSL/BM 

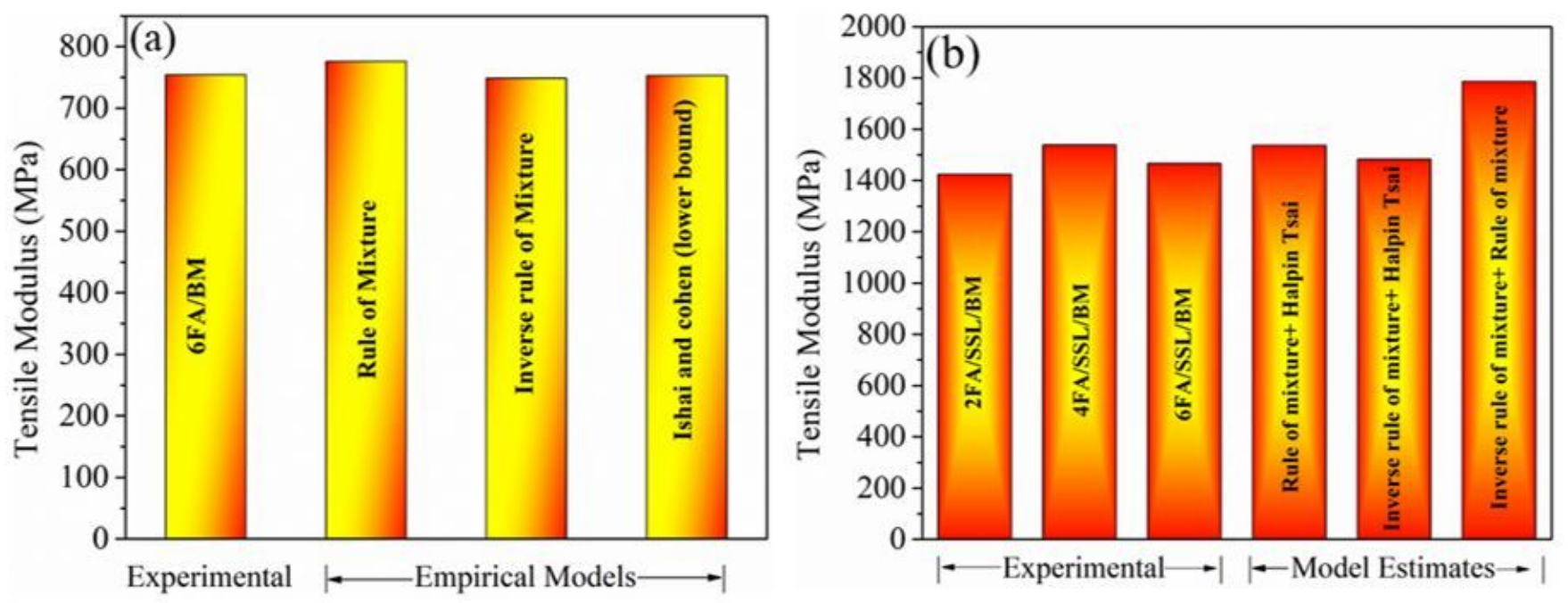

\section{Figure 3}

A comparative study between experimental vs theoretical tensile modulus values (a) 5 wt.\% FA reinforced BM composite (b) 5 wt.\% FA hybridized sisal fiber reinforced composites 


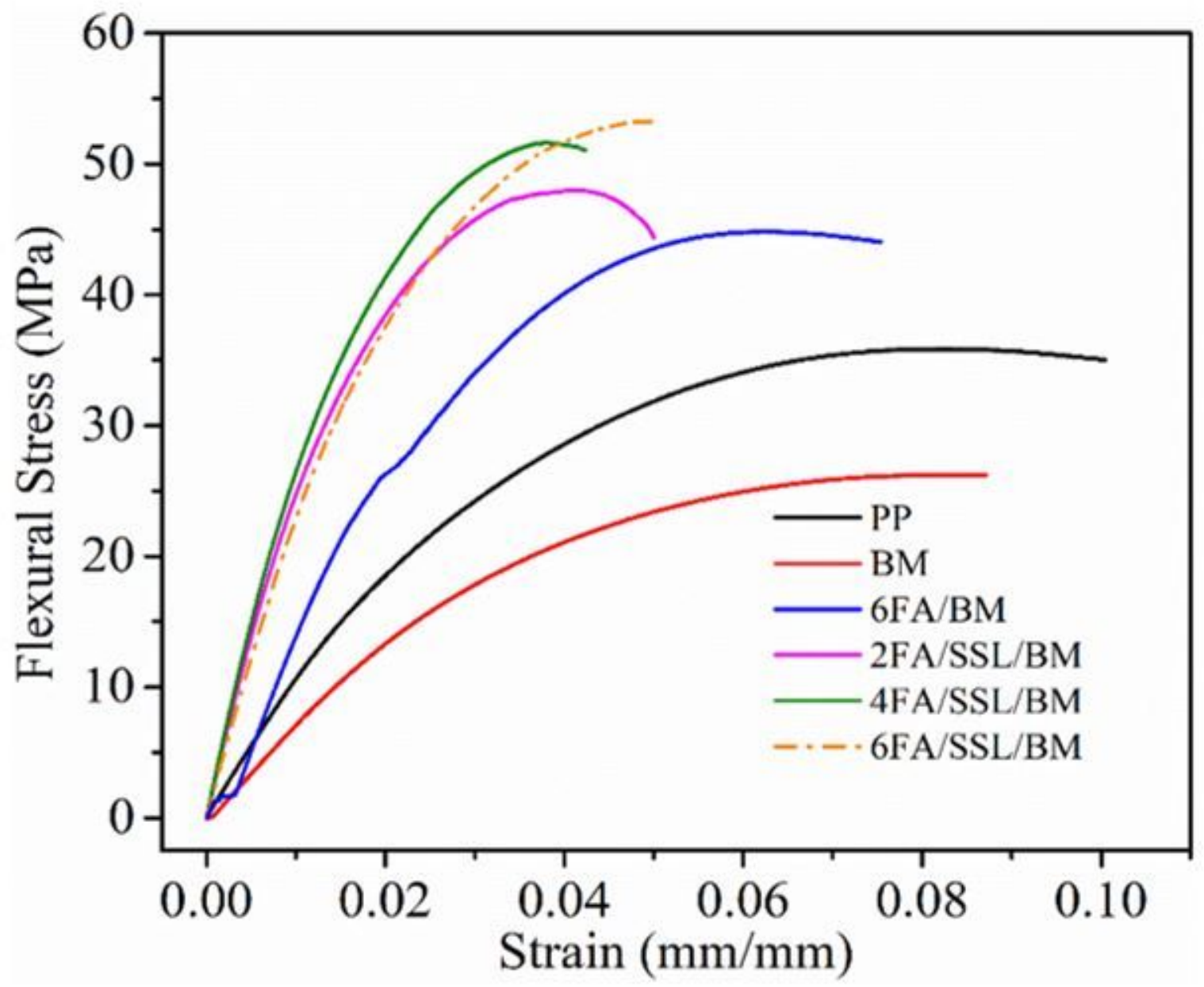

Figure 4

Flexural strength versus flexural strain for hybrid composites

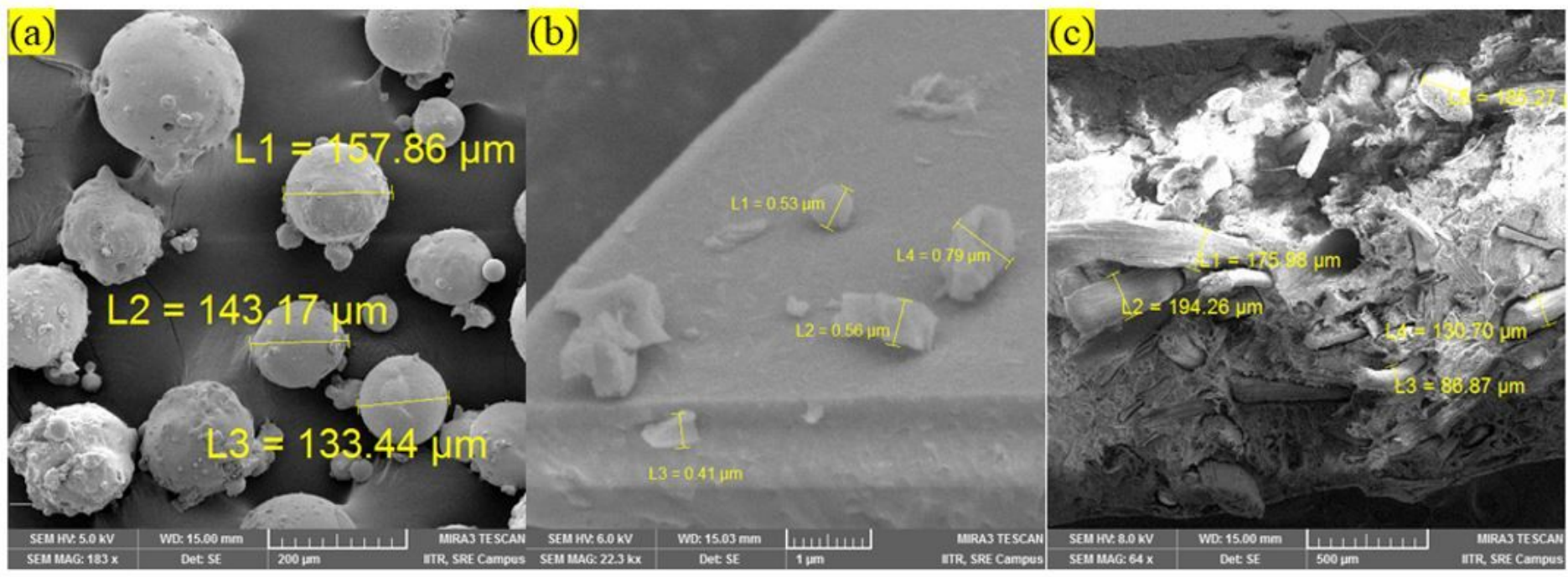


Figure 5

FESEM images of (a) Pristine FA (b) High energy ball milled FA (c) hybrid composite

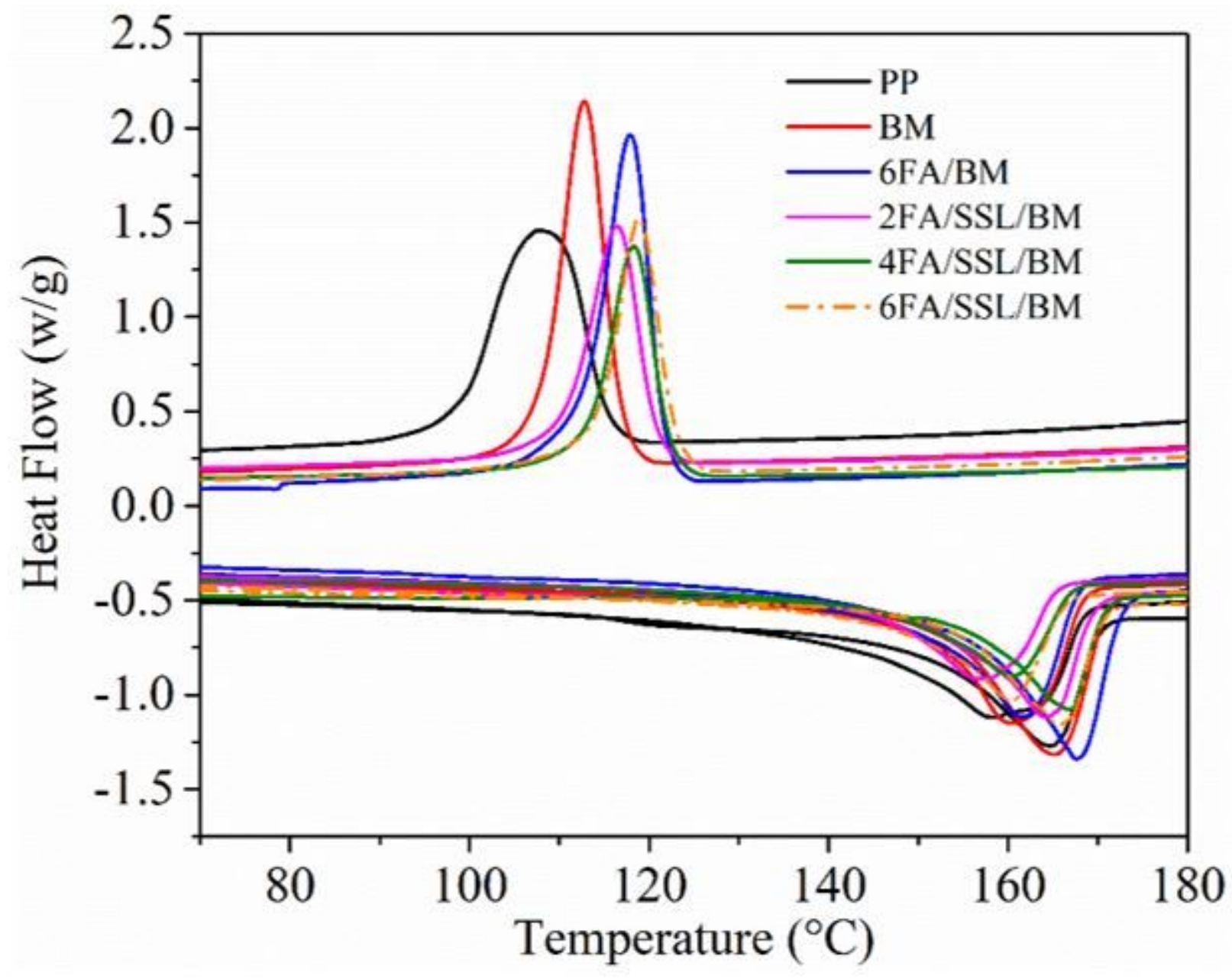

Figure 6

Illustration of the thermogram of the PP, BM, composite 6FA/BM, 2FA/SSL/BM, 4FA/SSL/BM and 6FA/SSL/BM composites 


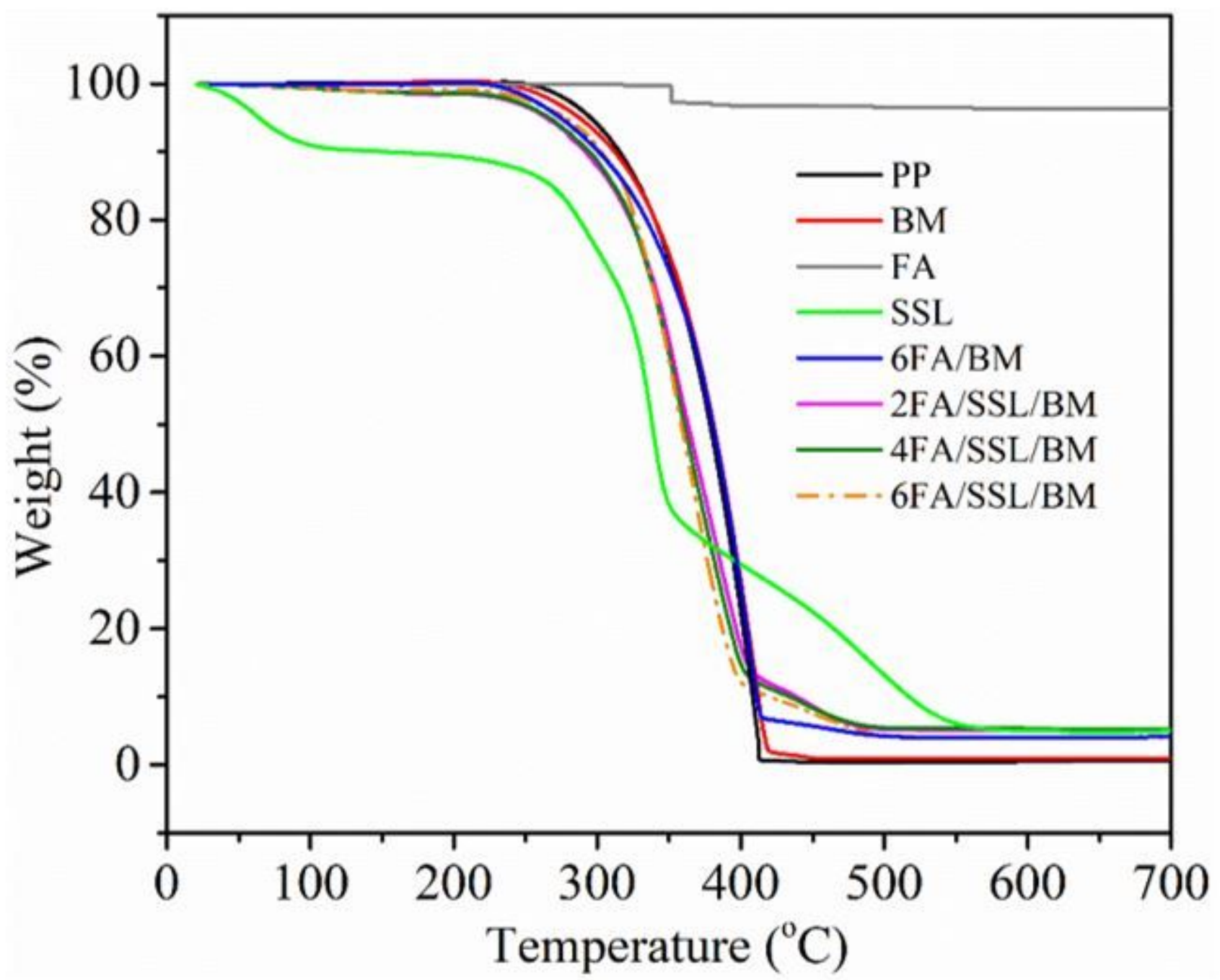

Figure 7

Thermogravimetric analysis of FA, sisal fiber, PP, and formulated hybrid composites.

\section{Supplementary Files}

This is a list of supplementary files associated with this preprint. Click to download.

- GraphicalAbstract.jpg

- Supplementary.docx 